\title{
Zn Loss into $\mathrm{ZnFe}_{2} \mathrm{O}_{4}$ in an Open Type Electric Arc Furnace: An In-Process Separation Performance Model
}

\author{
Thomas Suetens $^{1} \cdot$ Muxing Guo ${ }^{1} \cdot$ Karel Van Acker ${ }^{1} \cdot$ Bart Blanpain $^{1}$
}

Published online: 23 November 2015

(C) The Minerals, Metals \& Materials Society (TMS) 2015

\begin{abstract}
In order to reduce the burden of electric arc furnace dust on steel recycling plants, a new technology called in-process separation (IPS) was proposed. By separating $\mathrm{Zn}$ vapor from the solid particles in the electric arc furnace off-gas, production of Zn-containing electric arc furnace dust may be prevented. However, the spinel formation reaction at high temperatures and its impact on the technology's feasibility still require better understanding. This paper demonstrates a model that was developed to provide this insight, based on the results of our previous work on the kinetics of the spinel formation.This model evaluates the performance of IPS based on four key process parameters: the position of the separation unit, the timetemperature profile inside the off-gas duct, the solid particle size distribution, and the initial $\mathrm{Zn}$ and $\mathrm{Fe}$ content of the off-gas. The impact on the efficiency of each parameter was demonstrated using the results of the model for a specific off-gas treatment setup.
\end{abstract}

Keywords EAF dust $\cdot$ EAFD $\cdot$ In-process separation . Performance model $\cdot \mathrm{Zn}$ recycling $\cdot$ EAF off-gas

The contributing editor for this article was Shin-ya Kitamura.

Thomas Suetens

thomas.suetens@gmail.com

1 Department of Materials Engineering, KU Leuven, Kasteelpark Arenberg 44, Box 2450, 3001 Leuven, Belgium

\section{List of Symbols}

\section{Variables}

vol\% Volume percent

wt $\%$ Weight percent

C Zn concentration (wt \%)

$t \quad$ Time (s)

$r \quad$ Distance $(\mathrm{m})$

$R \quad$ Particle radius (m)

$D \quad$ Diffusion coefficient $\left(\mathrm{m}^{2} / \mathrm{s}\right)$

$R \quad$ Universal gas constant $\left(\mathrm{J} \mathrm{mol}^{-1} \mathrm{~K}^{-1}\right)$

$m \quad$ Mass $(\mathrm{g})$

$V \quad$ Volume $\left(\mathrm{cm}^{3}\right)$

$\rho \quad$ density $\left(\mathrm{g} / \mathrm{cm}^{3}\right)$

$[X] \quad$ Concentration of element $X(w t \%)$

$\mathrm{Zn} \quad$ Amount of $\mathrm{Zn}(\mathrm{g})$

$\mathrm{Fe} \quad$ Amount of $\mathrm{Fe}(\mathrm{g})$

$\eta \quad$ Efficiency

\begin{tabular}{|c|c|}
\hline Subscript & \\
\hline 0 & At $\mathrm{t}=0 \mathrm{~s}$ \\
\hline $\min , \max$ & Minimum, maximum \\
\hline ox & In the iron oxide particles after the reaction \\
\hline $\mathrm{T}$ & $\begin{array}{l}\text { In the total composition of an arbitrary amount } \\
\text { of EAF off-gas }\end{array}$ \\
\hline$i$ & Counter, for the $i$-th shell \\
\hline loss & $\begin{array}{l}\text { Relative amount lost to iron oxide fraction due } \\
\text { to the reaction }\end{array}$ \\
\hline air & Air intake into the off-gas duct \\
\hline EAF & EAF off-gas intake into the off-gas duct \\
\hline slag & $\begin{array}{l}\text { In the slag phase in the normally produced } \\
\text { EAFD }\end{array}$ \\
\hline
\end{tabular}


oxid In the iron oxide phase in the normally produced EAFD

EAFD In the normally produced EAFD

\section{Introduction}

When galvanized steel scrap is recycled, zinc-containing electric arc furnace (EAF) dust (EAFD) is produced. Since $50 \%$ of all produced zinc is used in galvanizing [1], EAFD plays a key role in the life cycle of zinc. Multiple methods exist to treat EAFD, aiming for high metal recovery and reduction of the amount of material sent to landfills. The historically preferred Waelz Kiln is still standing strong as the leading process with an EAFD treatment market share over $80 \%$ [2]. Unfortunately, the technology leads to the production of Waelz slag, which is often sent to landfill due to lack of an application. As a radical alternative to the traditional posttreatment approach, Ma [3] and Furuuchi et al. [4] have proposed to separate $\mathrm{Zn}$ and $\mathrm{Fe}$ into different streams before they form EAFD in the off-gas treatment system. This separation strategy was labeled In-process separation (IPS). Under normal operating conditions, EAF off-gas leaves the furnace as a gas mixture containing metallic $\mathrm{Zn}$ vapor along with steel and slag droplets. Theoretically, a pure zinc vapor can be obtained by collecting dust at a high temperature before the zinc can react or precipitate. The $\mathrm{Zn}$-containing stream would need to be treated for halides, but can then be sold to $\mathrm{Zn}$ smelters, while the Fe-containing stream can be returned to the EAF. Therefore, the addition of a separator unit to the EAF off-gas treatment system could replace the need for a resource intensive post-treatment plant.

In the setup discussed by Furuuchi et al. [4], a coke bed filter was used in combination with a sealed-type EAF furnace. However, most EAF systems are currently operated as open type systems [5]. Conversion to a sealed-type system has a big impact on the operation condition and will increase the cost to implement IPS. In order to be compatible with off-gas with a much higher $\mathrm{p}_{2}$ (due to air intake of an open system) an alternative dust capture system needs to be considered.

To understand the requirements of this dust capture system, the authors of this work already considered the thermodynamics and kinetics of the open system EAF off-gas. Unlike the first IPS feasibility assessment [3], we included the air intake and the presence of iron oxide particles in the off-gas. We found that, thermodynamically, $\mathrm{Zn}$ vapor will react with magnetite to form franklinite (Reaction 1) [6].

$$
3 \mathrm{Zn}(\mathrm{g})+2 \mathrm{Fe}_{3} \mathrm{O}_{4}(\mathrm{~s})+2 \mathrm{O}_{2}(\mathrm{~g}) \Rightarrow 3 \mathrm{ZnFe}_{2} \mathrm{O}_{4}(\mathrm{~s})
$$

In order to understand the impact of this reaction on the composition of the solid particles in the EAF off-gas, the reaction kinetics were studied and diffusion coefficients describing the reaction were found [7].
In this article, a model is presented that enables calculation of the $\mathrm{Zn}$ metal recovery in an open type EAF offgas treatment system. Since any $\mathrm{Zn}$ losses from the vapor phase to the solid particle fraction will reduce the IPS Zn recovery efficiency, the model can also be used to determine and maximize the $\mathrm{Zn}$ recovery efficiency for any given EAF plant through IPS.

\section{Modeling Procedure}

\section{Assumptions}

The following educated assumptions were made to support the model: (1) the slag particles in the off-gas do not react with the $\mathrm{Zn}$ vapor, (2) the outer shell of the iron oxide particles consists of magnetite, (3) all particles react with a constant $\mathrm{Zn}$ activity at the surface, (4) the complete particle surface is available for the reaction, (5) all iron oxide particles are perfectly spherical, (6) the diffusion coefficient is constant throughout the whole particle, and (7) the endpoint of the calculation represents particle capture and thus the end of the $\mathrm{Zn}$ diffusion.

\section{Approximation}

The final efficiency result is also based on the approximation that franklinite formation is the only cause for $\mathrm{Zn}$ losses. This approximation is reasonable since, even for typical EAF air intake ratios, metallic $\mathrm{Zn}$ is thermodynamically stable compared to $\mathrm{ZnO}$ at high temperatures $\left(>1300{ }^{\circ} \mathrm{C}\right)$ [6]. At lower temperatures, $\mathrm{ZnO}$ will become more stable. However, we did not consider the free $\mathrm{ZnO}$ particles lost to the solid fraction because the particles formed through oxidation of $\mathrm{Zn}$ vapor are sub-micron-sized $[8,9]$ and particles of this size are hard to capture using known dust capture technologies.

Any $\mathrm{Zn}$ lost to $\mathrm{ZnO}$ formation of the surface of other particles does contribute to the actual $\mathrm{Zn}$ losses. However, due to the difficulty in calculating this amount, it was not included in this work. Therefore, the reported losses in this work provide a best-case scenario that only considers the losses into $\mathrm{ZnFe}_{2} \mathrm{O}_{4}$.

\section{Input Parameters}

To use this model, some plant-specific information is required.

- The time-temperature profile of off-gas in the off-gas duct.

- The particle size distribution of the particles between 1 and $40 \mu \mathrm{m}$. 
- The composition of EAFD currently produced at the plant. More specifically, the distribution of Fe over Feoxide and slag particles (A), and the total $\mathrm{Zn} / \mathrm{Fe}$ ratio (B).

It is possible that the temperature in the off-gas ducts rises above $1700{ }^{\circ} \mathrm{C}$ [10]. However, in previous work, we already found that the formation of $\mathrm{ZnFe}_{2} \mathrm{O}_{4}$ only starts at temperatures lower than $1500{ }^{\circ} \mathrm{C}$ for the average zinc vapor pressure present in EAF off-gas [6]. Therefore, only time spent below $1500{ }^{\circ} \mathrm{C}$ was considered when determining the time-temperature profile.

\section{Calculation Method}

The model is based on 5 steps as shown in Fig. 1.

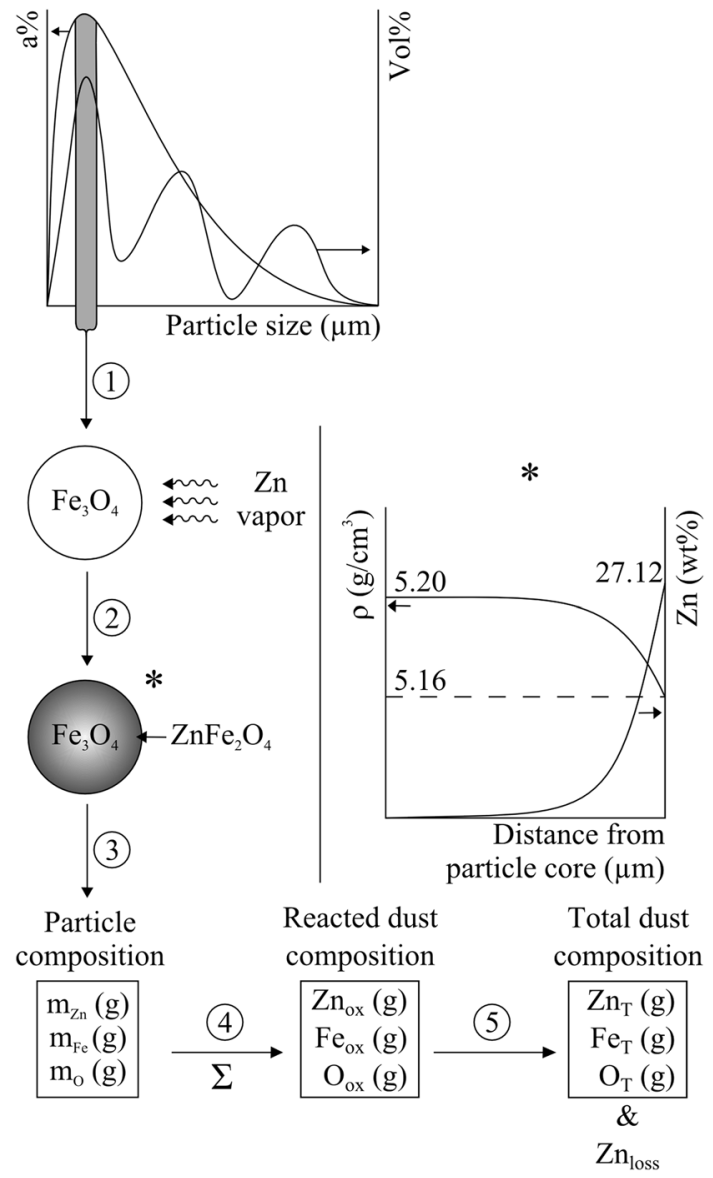

Fig. 1 Schematic illustration of the calculation method used in the kinetic model. The model is based on (1) distribution of the reacting iron oxide particles in size classes, (2) diffusion calculation of $\mathrm{Zn}$ in magnetite spheres, (3) particle composition determination, (4) summation over all particle size classes to obtain the reacted dust composition, and (5) calculation of the total dust composition and the relative $\mathrm{Zn}$ loss to the solid particle fraction for an arbitrary amount of EAF off-gas. The $*$ symbol in the Figure links the visual representation of the sphere to the graph on side showing the density and concentration profile of this sphere
(1) The reactive iron oxide particles are distributed in size classes. All particles in a size class are considered to have the same particle size. If the particle distribution is given in vol\%, the values are converted to absolute abundance (number of particles) per particle size.

(2) For each cluster, the diffusion of $\mathrm{Zn}$ into magnetite is then calculated by solving the diffusion equation for a spherical symmetry. As we consider the diffusion coefficient to be constant throughout the particle, the diffusion equation can be written as

$$
\frac{\partial C}{\partial t}=D \frac{1}{r^{2}} \frac{\partial}{\partial r}\left(r^{2} \frac{\partial C}{\partial r}\right)
$$

The following initial (I.C.) and boundary conditions (B.C.) were used (see Fig. 2 for dimensions):

\begin{tabular}{llll}
\hline I.C: & For $t \leqslant 0$ & $0 \leqslant r \leqslant \mathrm{R}$ & $\mathrm{C}_{0}=0 \mathrm{wt} \% \mathrm{Zn}$ \\
B.C.1: & For $t \geqslant 0$ & $r=\mathrm{R}$ & $\mathrm{C}=27.12 \mathrm{wt} \% \mathrm{Zn}$ \\
B.C.2: & For $t \geqslant 0$ & $r=0$ & $\partial C / \partial r=0$ \\
\hline
\end{tabular}

A time and spatial resolution of $0.1 \mathrm{~ms}$ and $0.1 \mu \mathrm{m}$ were used, respectively. The value $27.12 \mathrm{wt} \%$ was used as it is the maximum $\mathrm{Zn}$ content of $\mathrm{ZnFe}_{2} \mathrm{O}_{4}$.

By defining the temperature $T$ (in $\mathrm{K}$ ) as a function of time (in $\mathrm{ms}$ ):

$$
T=T_{\max }-\frac{T_{\max }-T_{\min }}{t_{\max }} \times t
$$

The time dependence of the diffusion coefficient obtained in our previous work (Eq. 4) [7] can be accounted for. This allows the implementation of the time-temperature profile into the model.

$D=1.4 \times 10^{-9} \times \exp ^{\left(-\frac{123 \times 10^{3}}{R \times \mathrm{T}}\right)}$

with $R$ the universal gas constant $\left(\mathrm{J} \mathrm{mol}^{-1} \mathrm{~K}^{-1}\right)$.

In the case of changing cooling rates, the diffusion equation needs to be solved in multiple steps. For each step the boundary conditions remain the same, but starting from

Fig. 2 Schematic 2D representation of the magnetite particle

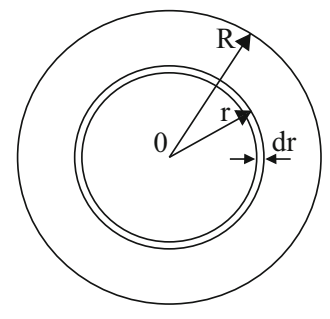


the second step, $\mathrm{C}_{0}$ in the initial condition is defined as the solution from the previous step. The cooling rate can be defined for each step using Eq. (3).

(3) From the obtained $\mathrm{Zn}$ concentration and density profiles, the particle compositions are obtained. Based on the calculated density values of $5.2 \mathrm{~g} / \mathrm{cm}^{3}$ (magnetite) and $5.163 \mathrm{~g} / \mathrm{cm}^{3}$ (franklinite) [11], a density profile can be obtained as a function of the $\mathrm{Zn}$ content as shown in the insert graph of Fig. 1. Each particle is considered as the sum of thin $(0.1 \mu \mathrm{m})$ shells and the particle composition can be found as

$$
m_{X}=\sum_{i} V_{i} \times \rho_{i} \times[X]_{i}
$$

In which $m_{X}$ stands for the mass of element $X(\mathrm{Zn}, \mathrm{Fe}$, or $\mathrm{O}), V$ for volume, $\rho$ for density, $[X]$ for the concentration of that element, and $i$ for the $i$-th shell.

(4) The total composition of the reacted dust can then be obtained by summation over all particle sizes, multiplied with their abundance.

(5) Finally, the composition of the EAFD produced in the studied plant is used as illustrated in Fig. 3. The input parameters A and B as defined in Sect. 2.3 were used.

The total amount of $\mathrm{Fe}$ in an arbitrary amount of off-gas can be obtained by

$\mathrm{Fe}_{T}=\mathrm{Fe}_{\text {ox }}+\mathrm{Fe}_{\text {ox }} \times A$

From this $\mathrm{Fe}_{T}$ value, $\mathrm{Zn}_{T}$ can be found through the conservation of mass:

$\mathrm{Zn}_{T}=\mathrm{Fe}_{T} \times B$

The $\mathrm{Zn}$ loss ratio and maximum IPS $\mathrm{Zn}$ recovery efficiency $(\eta)$ are given by:

$$
\begin{aligned}
& \mathrm{Zn}_{\text {loss }}=\mathrm{Zn}_{\text {ox }} / \mathrm{Zn}_{T} \\
& \eta=1-\mathrm{Zn}_{\text {loss }}
\end{aligned}
$$

Filling in (6) and (7) into (8) leads to the final equation of the model:

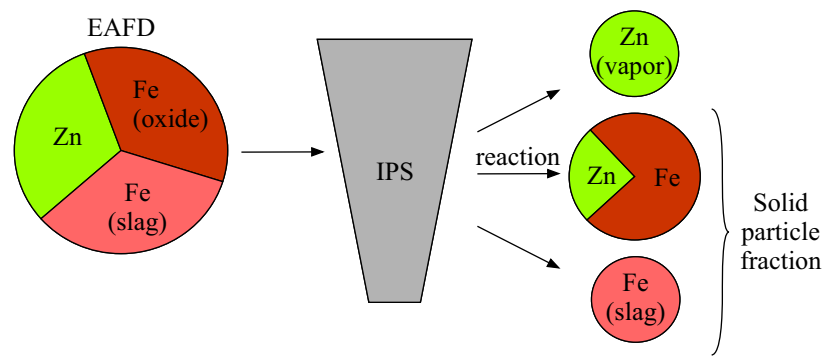

Fig. 3 The relation between the EAFD composition and the IPS products. The $\mathrm{Fe}$ in the slag phase was considered separately because it does not react with $\mathrm{Zn}$
$\mathrm{Zn}_{\text {loss }}=\frac{\mathrm{Zn}_{\mathrm{ox}}}{\mathrm{Fe}_{\mathrm{ox}} \times(1+A) \times B}$

In which $\mathrm{Fe}$ and $\mathrm{Zn}$ stand for the amount of $\mathrm{Fe}$ and $\mathrm{Zn}$ in a stream defined by the subscript, respectively (in g). The subscripts $T$, ox, and loss, stand for the total composition of an arbitrary amount of EAF off-gas, the iron oxide particles after the reaction, and the relative amount lost to iron oxide fraction due to the reaction, respectively.

\section{Evaluation of an Off-Gas Treatment System}

\section{The Time-Temperature Profile}

The post-combustion system described by Kirschen et al. [12] was selected to evaluate the effect of different process parameters on the IPS Zn recovery efficiency. In this system, the majority of the EAF off-gas is collected in a 38-mlong hot gas duct with a strongly regulated air to EAF offgas intake volume ratio $\left(\mathrm{V}_{\text {air }} / \mathrm{V}_{\mathrm{EAF}}\right)$. The temperature of the off-gas in the off-gas treatment duct strongly depends on this ratio as can be seen in Fig. $4 \mathrm{a} . \mathrm{V}_{\text {air }} / \mathrm{V}_{\mathrm{EAF}}$ intake ratios of $1.5,2.0$, and 4.0 were selected for this study. While 1.52.0 represent the ideal post-combustion operation ratios, sometimes intake ratios higher than 2.0 are allowed to ensure complete post-combustion before cooling. Using a constant gas flow rate of $40 \mathrm{~m} / \mathrm{s}$ in the ducts [12] and considering the reaction starting temperature of $1500{ }^{\circ} \mathrm{C}$, we obtained the time-temperature profiles used in this work (Fig. 4b). For each profile three cooling rates were identified. Therefore, all calculations in Sect. 4.2 are performed in 3 steps.

\section{The Particle Size Distribution}

The EAFD from the Esch-Belval ArcelorMittal plant characterized in our previous work has a fairly uniform particle size distribution from 0.7 to $40 \mu \mathrm{m}$ [6]. Dust with a higher abundance of small supra-micron particles has also been reported [8]. To understand the impact of particle size on the outcome of our model, four different particle size distributions were used in this work:

- Real: the observed particle size distribution

- Small: a gamma distribution $(\alpha=2, \beta=3)$

- Large: the horizontal mirror image of the small distribution

- Uniform: a constant vol\% for all particle sizes

All distributions were defined for 27 particle sizes (Table 1) in vol\% and are shown in Fig. 5. These are the values used by a Mastersizer Microplus (Malvern Instruments) to report particle size distributions. 

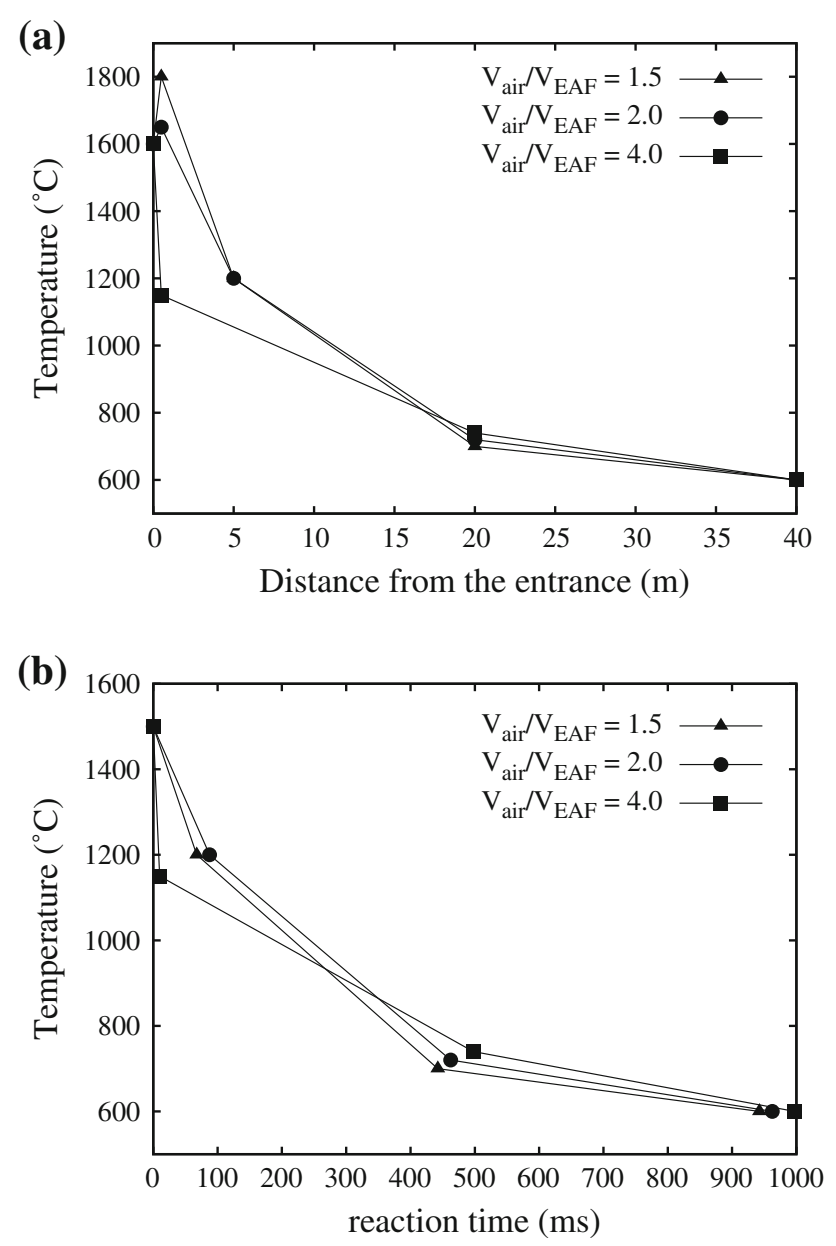

Fig. 4 Temperature profiles inside the off-gas treatment duct for three air to off-gas intake ratios. a the temperature as a function of the distance from the entrance as derived from Kirschen et al. [12], and b temperature as a function of the reaction time

Table 1 The 27 used particle sizes (in $\mu \mathrm{m}$ )

\begin{tabular}{lllllllll}
\hline 0.78 & 0.91 & 1.06 & 1.24 & 1.44 & 1.68 & 1.95 & 2.28 & 2.65 \\
3.09 & 3.60 & 4.19 & 4.88 & 5.69 & 6.63 & 7.72 & 9.00 & 10.48 \\
12.21 & 14.22 & 16.57 & 19.31 & 22.49 & 26.20 & 30.53 & 35.56 & 41.43 \\
\hline
\end{tabular}

\section{The EAFD Composition}

In general, the EAFD zinc content can vary from around $4-35 \mathrm{wt} \%$, while iron varies from 25 to $50 \mathrm{wt} \%$. The total sum of the zinc and iron oxides in the dust remains constant around $70 \mathrm{wt} \%$ [6]. The Esch-Belval dust is a zinc rich dust with a zinc and iron content of 27 and $29 \mathrm{wt} \%$, respectively. To understand the impact of the EAFD composition on the model, eight artificial dust compositions were used (Table 2).

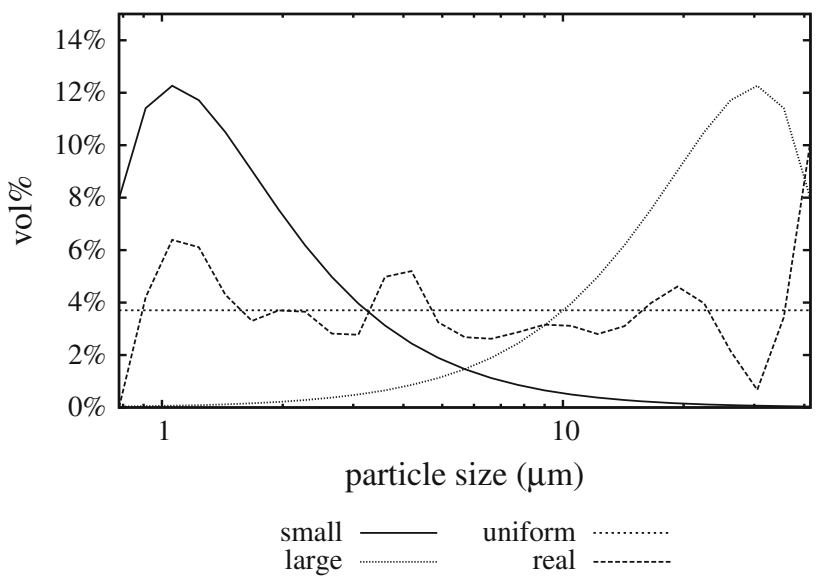

Fig. 5 The four particle size distributions used in this work, each defined by 27 particle sizes

The distribution of $\mathrm{Fe}$ over Fe-oxide and slag particles might be the most difficult parameter to determine. From our previous characterization study we found that the slag particles consist of two phases. Instead of a localized phase composition, the average slag composition is taken. By scaling one of the typical slag elements $(\mathrm{Ca})$ to the total dust composition, the total weight content of Fe in the slag phase can be obtained. For Esch-Belval dust, a value of $6 \mathrm{wt} \%$ was found. This translates to a $\mathrm{B}$ ratio of 0.26 . Values from 0 to 4 with a 0.5 increase step were used to test the sensitivity.

\section{Results and Discussion}

All Figures in this section are used to illustrate the impact of the studied process parameters on the zinc losses. The initial increase in $\mathrm{Zn}$ loss at the start of the reaction is due to the first boundary condition of the model where a surface concentration is imposed for all particles at the start of the reaction.

\section{The Impact of Distance and the Time-Temperature Profile}

Through the time-temperature profile, the diffusion coefficient is defined at each point in the off-gas duct. Spending a longer time at high temperatures will result in higher $\mathrm{Zn}$ losses to the solid fraction. Figure 6 shows the calculated

Table 2 The $\mathrm{Zn}$ and Fe content of the artificial dust compositions (in wt \%) [13]

\begin{tabular}{lllllllll}
\hline $\mathrm{Zn} / \mathrm{Fe}$ ratio (B) & 0.11 & 0.23 & 0.39 & 0.59 & 0.72 & 0.83 & 1.15 & 1.59 \\
\hline $\mathrm{Zn}(\%)$ & 5 & 10 & 15 & 20 & 23 & 25 & 30 & 35 \\
$\mathrm{Fe}(\%)$ & 47 & 43 & 38 & 34 & 32 & 30 & 26 & 22 \\
\hline
\end{tabular}


$\mathrm{Zn}$ loss values for the three profiles defined in Fig. 4b. The real particle distribution was used as a fixed parameter, along with the Esch-Belval dust composition.

Figure 6 clearly shows that the initial cooling rate of the dust is crucial to minimize $\mathrm{Zn}$ losses. Even though the $\mathrm{V}_{\text {air }} /$ $\mathrm{V}_{\mathrm{EAF}}$ ratio of 4.0 is a less efficient ratio when it comes down to heat recovery from post-combustion [12], the initial high cooling rate has a high impact on the IPS efficiency. The second cooling rate is less steep and the temperature of the off-gas even becomes higher than for the optimal post-combustion air intake ratios. This results in higher reaction rates for the second calculation step (as can be seen in Fig. 6). The total impact of this second step is still noteworthy, but no longer as defining for the total efficiency as found in the first step. Finally, the last calculation step only marginally contributes to the $\mathrm{Zn}$ losses. Even though the low temperatures make the reaction even more favorable thermodynamically, the kinetics are hindered too much to lead to a significant reaction rate.

Considering Fig. 4a, one might think the $\mathrm{V}_{\text {air }} / \mathrm{V}_{E A F}$ ratio of 1.5 should have resulted in the most $\mathrm{Zn}$ losses due to the higher temperatures. However, because of our assumption that the reaction only starts at $1500{ }^{\circ} \mathrm{C}$, the higher cooling rate at high temperature of this air intake ratio results in a shorter time at a high temperature below $1500{ }^{\circ} \mathrm{C}$. Therefore, this air intake ratio actually has a more optimal timetemperature profile than the $\mathrm{V}_{\text {air }} / \mathrm{V}_{\mathrm{EAF}}$ ratio of 2.0 (Fig. 4b).

\section{The Impact of the Particle Size Distribution}

Through diffusion, zinc enters the iron oxide particles over time to form $\mathrm{ZnFe}_{2} \mathrm{O}_{4}$. Its easy to understand that smaller particles will saturate faster because the diffusion distances are shorter. Therefore, a particle distribution with a higher

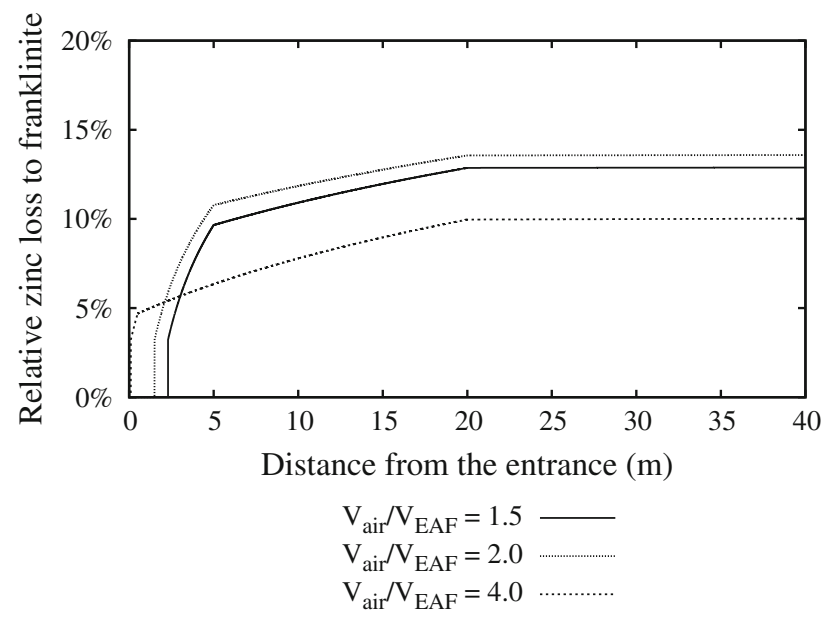

Fig. 6 The impact of the time-temperature profile on the relative zinc loss to franklinite relative amount of smaller particles will lead to higher $\mathrm{Zn}$ losses. This effect can clearly be seen in Fig. 7, which shows the calculated $\mathrm{Zn}$ loss values for the time-temperature profile of the $\mathrm{V}_{\text {air }} / \mathrm{V}_{\mathrm{EAF}}$ ratio of 4.0 and the real EschBelval dust composition. Preventing the formation of small iron oxide particles that end up in the off-gas will greatly improve the IPS efficiency.

Despite having multiple peaks in its particle size distribution, the Esch-Belval dust behaves nearly identical to the uniform particle size distribution. This can be attributed to the fact that it contains both a lot of small and large particles.

\section{The Impact of the Initial $\mathrm{Zn}$ and Fe Content of the Off-gas}

The effect of the dust composition on the IPS efficiency can directly be derived from Eqs. (9) and (10). The Zn loss results relates to the $\mathrm{Fe}_{\text {slag }} / \mathrm{Fe}_{\text {oxid }}$ ratio as $1 /(1+\mathrm{A})$, and to the $\mathrm{Zn}_{\mathrm{EAFD}} / \mathrm{Fe}_{\mathrm{EAFD}}$ ratio as $1 / \mathrm{B}$. These relationships are visually shown in Fig. 8.

Obviously, for an off-gas stream with a lower $\mathrm{Zn}$ content, each loss represents a higher relative $\mathrm{Zn}$ loss than for higher $\mathrm{Zn}$ content off-gasses. Unless IPS can be implemented close to the entrance of the off-gas treatment system, the $\mathrm{Zn}$ recovery efficiency will be very low for low $\mathrm{Zn}$ EAFD producing plants.

Although the effect of the Fe distribution over the slag and oxide phase is smaller than that of the total $\mathrm{Zn}$ content, adjustment of this parameter does not require changing the furnace input streams. Having Fe more in the slag than in the iron oxide particles in the off-gas can reduce the $\mathrm{Zn}$ losses by a factor of 5 as can be seen from Fig. 8. By operating the EAF under conditions that prevent iron particles to escape from the furnace bath, $\mathrm{Zn}$ has less iron oxide material to diffuse into.

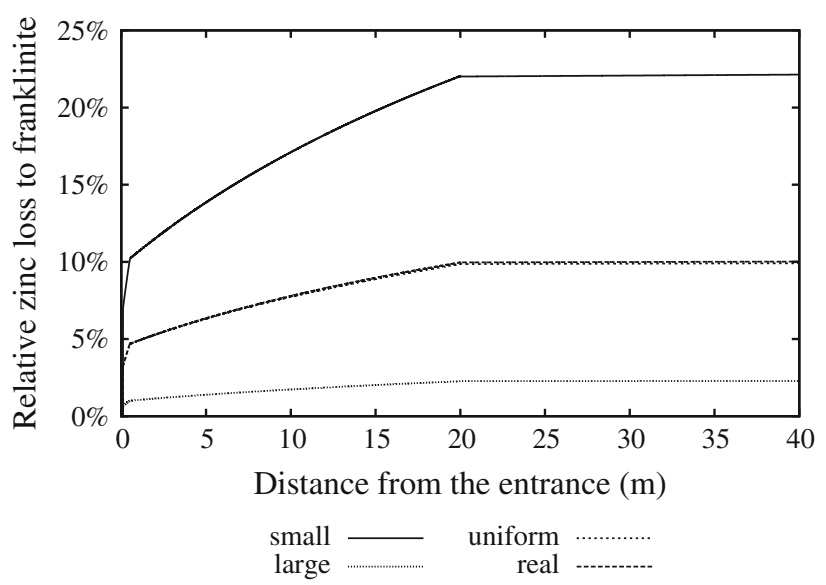

Fig. 7 The impact of the particle size distribution on the relative zinc loss to franklinite 


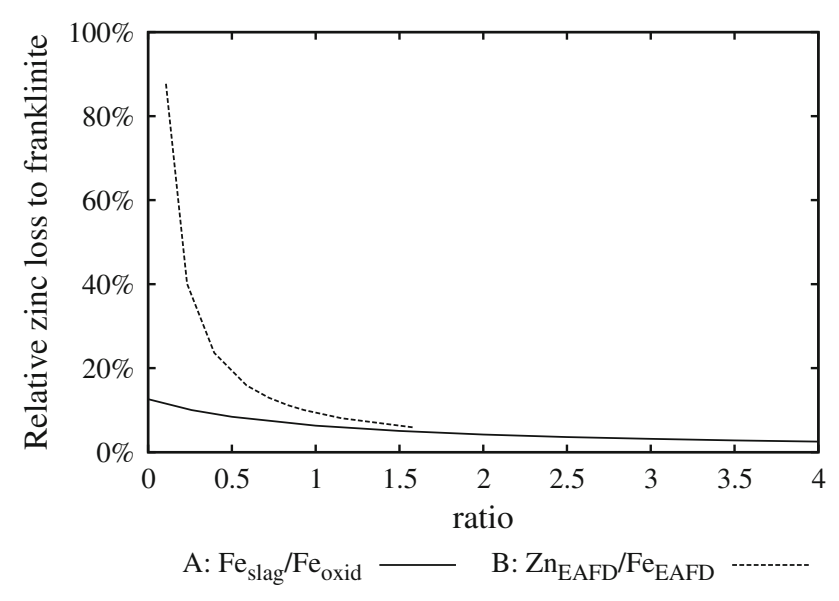

Fig. 8 The impact of the initial EAFD composition on the relative zinc loss to franklinite at the end of the off-gas treatment system (40 $\mathrm{m}$ from the duct entrance)

\section{Conclusion}

A model was developed that can calculate the performance of the new IPS technology.

One of the most important decisions that must be made when implementing this technology will be its position in the off-gas treatment system. The ideal position for the IPS system would be as close to the entrance as possible. Not only do the particles have less time to react, but the high temperatures in the initial meters lead to the fastest reaction rates and a large fraction of the $\mathrm{Zn}$ losses. However, high temperatures and space limitations might render this option too costly. Therefore, the position will be decided more by feasibility than in function of the IPS efficiency.

The surprisingly positive result for the high air intake ratio operating conditions could have a large impact on how the EAF is operated. Even though the heat recovery from the post-combustion is less effective, this could be warranted by the increase in IPS efficiency.

As expected, small particles contribute more to overall zinc losses than the larger particles. Re-evaluation of the EAF operation conditions to minimize fine particle generation will further improve the IPS efficiency.

Finally, the model indicates that IPS should initially be used for high $\mathrm{Zn}$ EAFD producing plants. For the low $\mathrm{Zn}$ plants, the amount of $\mathrm{Zn}$ reacting with the iron oxide will lead to much larger relative losses, resulting in very low IPS $\mathrm{Zn}$ recovery efficiencies. This effect is much smaller for plants with a high $\mathrm{Zn}$ content, making them ideal candidates for pilot plant testing of the technology.

Acknowledgments This study was conducted as a part of the research supported by $\mathrm{CR}^{3}$, Center for Resource Recovery and Recycling an Industry/University Cooperative Research Center (I/ UCRC) supported by NSF. The authors thank all center members who have supported this study.

\section{References}

1. International Zinc Association (2011) Zinc uses. http://www.zinc. org/basics/zinc_uses. Accessed 10 Jan 2015

2. Piret NL (2012) EAF dust processing: rotary hearth a potential substitute for the Waelz Kiln? World Metall Erzmetall 65(5):306

3. Ma N (2011) On in-process separation of zinc from EAF dust. In: Monteiro S, Verhulst D, Anyalebechi P, Pomykala J (eds) EPD Congress 2011. The Minerals, Metals \& Materials Society, Warrendale, PA; John Wiley \& Sons, Hoboken, NJ, pp 947-952

4. Furuuchi M, Kanaoka C, Hata M, Kawaminami Y (2002) In: Proceedings of 5 th int. symp. gas cleaning at high temperatures, Morgantown, pp 17-20

5. Commission European (2011) Directorate-general for research and innovation, improved EAF process control using on-line offgas analysis. Publications Office of the European Union, Luxembourg

6. Suetens T, Guo M, Van Acker K, Blanpain B (2015) Formation of the $\mathrm{ZnFe}_{2} \mathrm{O}_{4}$ phase in an electric arc furnace off-gas treatment system. J Hazard Mater 287:180-187

7. Suetens T, Guo M, Van Acker K, Blanpain B (2015) Gas-solid reaction kinetics of $\mathrm{ZnFe}_{2} \mathrm{O}_{4}$ formation from 907 to $1100{ }^{\circ} \mathrm{C}$. J Phys Chem A 119:4718-4722

8. Bruckard WJ, Davey KJ, Rodopoulos T, Woodcock JT, Italiano J (2005) Water leaching and magnetic separation for decreasing the chloride level and upgrading the zinc content of EAF steelmaking baghouse dusts. Int J Miner Process 75(1):1-20. doi:10.1016/j. minpro.2004.04.007

9. Guézennec AG, Huber JC, Patisson F, Sessiecq P, Birat JP, Ablitzer D (2005) Dust formation in electric arc furnace: birth of the particles. Powder Technol 157(1):2-11. doi:10.1016/j.powtec. 2005.05.006

10. Commission European (2007) Directorate-general for research and innovation, development of operating conditions to improve chemical energy yield and performance of dedusting in airtight EAF. Publications Office of the European Union, Luxembourg

11. Jolyon R, Ida C (1993-2014) mindat.org - the mineral and locality database. www.mindat.org. Accessed 25 Dec 2014

12. Kirschen M, Velikorodov V, Pfeifer H (2006) Mathematical modelling of heat transfer in dedusting plants and comparison to off-gas measurements at electric arc furnaces. Energy 31(14):2926-2939. doi:10.1016/j.energy.2005.12.006

13. Suetens T, Klaasen B, Van Acker K, Blanpain B (2014) Comparison of electric arc furnace dust treatment technologies using exergy efficiency. J Clean Prod 65:152-167. doi:10.1016/j.jcle pro.2013.09.053 